ESTUDOS GERAIS

\title{
Conceito de Valorização Humana
}

José de Almeida Rios

\author{
INTRODUÇÃO
}

$\mathrm{E}$

NCONTRA-SE a Humanidade, na fase atual da Civilização que desfrutamos em uma terrivel encruzilhada, cuja decisão salvadora exige uma reformulação dos Valôres Humanos não mais visando apenas indivíduos, cidadãos ou personalidades; não mais atendendo classes, povos, Nações ou grupo de Nações, e mesmo raças. Tudo o que fôr preciso tentar, experimentar, executar ou atingir deverá ser feito. O problema deixou de ser apenas humano para ampliar-se no sentido da Humanidade. Eis a quanto nos conduziu uma simples disputa filosófica, entre Mestre e Discípulo - Platão e Aristóteles há cêrca de 2.300 anos. Desde então, congregando todos os esforços desenfrearam-se os homens pela filosofia sensorial relegando à margem a integração dos valôres espirituais, sentimentais e intelectuais voltados ao interêsse do Homem. Hoje temos que considerar êste simplesmente como animal, como consumidor ou criador de riquezas ou como comparsa social ou cidadão responsável como uma atenção subsidiária daquela de o julgamento como de nossa própria natureza, com seus defeitos irredutiveis e redutivels.

Não se diga e não se pense que a negatividade deva existir ou estar ausente para que a afirmação se implante na sua fase evolutiva criadora. As duas fazem parte do antagonismo da vida e elas se sucederam obedecendo a Leis e métodos até então incontroláveis e misteriosos. Tanto poderemos vislumbrá-las na apreciação pela Síntese como identificá-las pela Análise. Os surtos de evolução econômica apresentam fases cíclicas negativas de origens não fundamentadas suficientemente pela Ciência. MALRAuX nega a sequiência das diversas Civilizações sem que possamos compreender as suas extinções sem o desaparecimento dos homens que as criaram. Contudo, chegamos hoje a uma evolução científica e técnica a que uma valorização negativa espiritual ou do pensamento poderá levar à destruição, não de uma Civiliza- 
ção, não de um Progresso, mas do sentido mais refinado do pensamento humano, que é a Ética ou o respeito à própria vida, como afirmou Albert Schwartz.

Cremos ter chegado o homem a fechar um Ciclo de sua capacidade material, restando-lhe agora o amplo campo do pensamento para expandir-se, procurando a trilha espiritual, a busca da Verdade. A reação materialista, que se seguiu a um longo período de coação sentimental e de consciência, produziu violentos resultados negativos, ultrapassando um grau favorável e criador de desequilibrio. As tradicionais fôrças sociais - Religião, Universidade e Classe Armada ainda se acham imbuídas dos vestígios coercitivos tradicionais e seletivos de que eram instrumento e acompanham muito timidamente a excepcional revolução social do presente momento. O problema ainda se torna mais angustiante quando se observa a violenta intromissão cultural, tendendo a uma incontrolável "sincretização", impondo reivindicações e direitos sem os atributos culturais evolutivos aconselháveis. O processo ainda se torna mais perigoso nos povos e Nações pouco amadurecidos, via de regra, verdadeiros caldeirões sociais em franca ebulição. Justamente nestes há a necessidade imperiosa de integração social das tradicionais fôrças sociais acima mencionadas. A "integração" significa servir e ser servido. Evidencia-se que as aspirações e inquietações de povos ainda em fase incipiente de evolução exigem alguns procedimentos e atitudes diferentes das fôrças tradicionais. Assim, pois, a caracteristica de "servir e ser servido" deverá diferir profundamente. $\mathrm{Na}$ filosofia dos conflitos e da ação de defesa nacional ocupa pla1io superior a Ciência e a T'écnica. Nas atividades sociais do Brasil de hoje ressaltarse a grande deficiência da qualificação profissional e técnica. Dispondo da ordem, da disciplina e de são nacionalismo, a classe armada ampliaria a sua tarefa de formação especializada. Sem desvirtuar o importante papel que lhe cabe, muito pelo contrário, aumentando os valôres humanos de Poder Nacional, estaria integrada nas aspirações e interêsses pátrios mais prementes. Nenhuma atividade social é mais indispensável ao Brasil de hoje do que a prática agricola racionalizada. Os recursos naturais condicionam a sua longevidade ao trato que os homens lhe propiciam. Estaria assim acorde com o gabarito de compreensão do povo a ação de «integração" de sua classe militar. A Universidade tem que mudar seus padrões de seletividade social atendendo ao preceito de justiça social de dar a mesma oportunidade a todos em quaisquer camadas sociais em que se encontrem. Tem que servir ao meio social melhorando em intercâmbio e convênios diretos as capacidades técnicas, assim como à guisa de seus trabalhos práticos investigar e estudar 
acêrca de condições e situações educacionais e mentais influenciando na sua esfera de jurisdição geocultural, corrigindo e atendendo a formação de seu material humano. A Religião mostrará menos intolerância e intransigência, indo ao encontro dos vícios e das deformações sociais, campo específico de sua luta. Viver intramuros encastoada na virtude, só criticando e deplorando, quando não julgando sem pesquisar as causas, aumenta a coorte de desesperos e desenganados. A par de atendimento aos necessitados materiais e espirituais, o grupo religioso poderá prestar serviços inestimáveis no setor pioneiro da educação escolar. $E^{\prime}$ preciso compreender que nos paises de incipiência cultural a matéria sobrepuja o espírito no comando das atitudes sociais e procedimentos sinceros. A Moral incultada de forma coercitiva e não convencional tem pouca base fundamental.

Aprisionado o homem no "Finito" visando o "Infinito"; estrangulado na fragmentação do "Relativo" a perseguir o "Absoluto"; confundido pela Felicidade que chora na Dor; surprêso pela "Sabedoria" encontrando-se com a "Ignorância" e estático da ameaça à vida pelo fruto de sua luta contra a Morte, sente Êle agora que precisa pensar no outro Homem. Cabe assim e sem tardança conceituar e atender a valorização do gênero humano.

\section{VALORIZAÇÃO DO HOMEM}

\section{Definição}

Valorizar o homem é propiciar-lhe elementos de melhor composição orgânica, adaptá-lo ao meio para que possa compreender e aceitar a convenção de renunciar a alguma coisa para o bemcomum.

\section{QUE SE ENTENDE POR VALORIZAÇÃO HUMANA}

Em princípio, resguardando a idéia da liberdade, sòmente o próprio individuo pode conceituar o que se compreende por valorização de sua personalidade. Decorre, pois, de imediato, que a prerrogativa de liberdade deveria ser a primeira idéia correta de valorização. Contudo, a vida social restringe ao indivíduo, em seu próprio benefício uma reformulação do conceito de valorização que êle outorgou a si próprio. Assim, contraditòriamente, a evolução cultural, finalidade social perseguida pelos esforços de valorização, cerceia e restringe cada vez mais a própria liberdade, condicionando a ao bem coletivo. Exatamente o que se observa com esforços da Educação Escolar, procurando destinar o indivíduo a sua correta aptidão e habilidade em benefício comum, 
pode entrar em conflito com a sua aspiração e interêsse. Dêste modo, não poderemos impor simplesmente ao individuo a aquisição de atributos e qualificação que o levem a um conceito de valorização, tal como o pretende a sociedade. Contudo, se antes da idade da determinação formos atendendo ao gênero humano na sua formação e evolução biológica, teremos muito maiores probabilidades de entrosá-lo no sistema criado pela sociedade para valorizá-lo. Temos na mente os conflitos anotados na História de nosso país quando foi instituída a vacinação obrigatória. Foi uma técnica destinada justamente a valorizar a pessoa humana em fator importante, qual seja a preservação da saúde. Realmente precisamos enfatizar na valorização a conservação da vida, considerada no senso comum o bem real de maior valor. Em seguida, o viver bem requer uma gama de requisitos indispensáveis, selecionados e hierarquizados pela sociedade, englobando fatôres espirituais, morais e materiais. Assim, o homem jurídico ou o ente social deve encarar seu semelhante como digno de satisfazer a um mínimo de necessidade para compor a vida dentro da integração dos fatôres que definem o conceito social de valorização. Pretendendo levar ao individuo aquelas exigências procura propiciar-lhe condições de viver bem, dentro do conceito social corrente do grupo social em tese. Como já dissemos, o homem é fruto de uma harmonia de fôrças biológicas dentro de desproporcões fisiológicas adequadas que condicionam todos os demais fatôres e desencadeiam as atitudes sociais; como podem comprometer a própria ação de valorização. Evidencia-se, pois, a necessidade de fiscalizar e atender ao gênero humano na sua formação, antes da idade da determinação. Estigmas, taras seriam acrescidos àqueles pré-existentes e oriundos na geração e da hereditariedade se atenções especiais não convergirem para as corrigir.

A adaptação social ao "mores" de Grupo acompanhada concomitantemente de meios suficientes para conseguir informações, iniciará o processo de transmissão da experiência acumulada, exercitando o pensamento para a determinação de serem conseguidos novos valôres culturais. A transmissão cultural obtida pela aquisição de meios de informações levará a outro homem a consciência dos valôres já incorporados e o resultado de novas aquisições conseguidas pelos grupos seletivos, ampliando as suas possibilidades de atender mais e melhor a seus desejos e aspirações, conforme sejam livremente ditadas pelo pensamento e pelas idéias próprias.

A informação e a posse de elementos conscientes de integração social leva ao individuo o sentido de abstenção e de restrição a certas prerrogativas de liberdade com que contribui para o 
senso comum de viver bem. Obedecendo a um minimo de obrigações e restrições determinadas pelo interêsse coletivo sòmente o indivíduo pode realmente escolher o conceito próprio de valor humano. Em verdade todo o valor e qualquer valorização apresentam caracteres profundamente relativos, sujeitos a condições, e proporções variáveis, elásticas e flexíveis no tempo e no espaço. Quanto mais evoluida uma sociedade maiores são as restrições e mais limitadas as prerrogativas individuais. Isto tem levado os filósofos a pensarem que a luta contra a natureza, fundamento intrinseco da valorização humana terá como fim último a vida harmônica do homem como meio. Esta harmonia apenas existe ainda na desarmonia dos homens nas suas sangrentas e episódicas lutas pela sobrevivência. Decorre disso que o fundamento de uma ação para valorizar o gênero humano está na preservação da vida orgânica. Dadas as demais categorias de valorização, mesmo a liberdade, estão condicionadas, tendo no tôpo da hierarquia, as condições biológicas favoráveis e a utilização de outras prerrogativas. Não poderemos enfatizar os valôres humanos subjetivos - liberdade de idéias e de pensamento, um padrão de moral satisfatório, a boa utilização da liberdade e a assimilação da própria vida que objetivamos ser bem vivida conforme os espécie que no homem se sublima na auréola sentimental pretere damento na vais fares. Considerando se esta hierarquia, o funsatisfação e incorporação do homem é conseguir para êle uma tos tendendo a aparação de outros valôres particulares e distinfazer livremente peus perseguir suas aspirações, satisprincipio de justiça social de: "ter eitar-se convencionalmente ao Mesmo aqui, a sociedade de: "ter e fazer o que lhe compete". tunidade a todos. A natureza obrigará a dispensar a mesma opormodo absolutamente A natureza humana se desenvolve e evolui de prevalentes de ente desigual outorgando a cada um categorias sempre depende da Razão Humanto global e sectorial. Nem prio arbítrio a satisfação do desejo em conseqüência, do próde valôres. Contudo, a qualificsejo de aumentar certa categoria uso da Razão, e por a qualificação de semelhante e animal com outros homens uma disciplina de julgar, tem que merecer de lar na desigualdade frentina de procedimentos tendendo a iguadentro dos padrões frente a requisitos minimos de viver bem, resultado do esfôrç de grupo social. A simples sobrevivência é o deveria ser osfôrço e do interêsse instintivo do irracional e nunca homem, ćonsidero a atingir na valorização humana. O próprio cursos necessários de o seu interêsse, dispensa ao animal os recursos necessários de sobrevivência e de reprodução, bem cuidada, 
inciusive a genética, somando fatôres de valor ao fruto de seu esfôrço, visando de sobejo a satisfação dos próprios desejos e da defesa de seus interêsses. Não é possivel, pois, na solidariedade social, como valorização humana e conquista simples de tais requisitos mínimos.

Nos séculos passados a mística religiosa e o destino sobrenatural dos governantes e dirigentes dos povos, conseguia de certo modo estabelecer uma atitude de concordância e conformação com a situação de desigualdades humanas. Dentro de certos limites, igualar condições e situações individuais é impossível, tendo em vista a valorização prevalente ligada a fundamentos biológicos que ultrapassam a Razão Humana. Atuando a Humanidade, em seu esfôrço de atender ao homem em suas aspirações e necessidades, encontra logo um fator negativo que se contrapõe a seus objetivos. Se considerarmos, porém, um, mínimo de existência digna e a disponibilidade de recursos com livre acesso a todos, cumprindo o postulado da mesma oportunidade, será possivel levar a todos condições precisas de um mínimo de vivência e bem-estar. Disto resulta que a moral impõe a concordância de serem igualados os homens pelos atributos e qualificações subjetivas, dado que na categoria objetiva ou material tem que ser considerado o fator prevalente de valorização, independente da Razão Humana. Devemos, pois, impor e igualar os homens pelo que valem como contribuição de sua atitude social em benefício de todos, encarecido pelo trabalho dignificado em qualquer de suas categorias. Ora, justamente a Razão Humana tem sido deformada e distorcida quanto os homens se esforçam, nos seus variados e diversificados grupos, em aperfeiçoar e pulverizar recursos com o objetivo de destruir as vidas humanas. Mistificadamente, assemelham-se ao irracional e comprovam a teoria filosófica de que o fim último do homem é a sua harmonia com a natureza. A luta pelo progresso e pela evolução da Humanidade, a pretensa construção da Civilização, nada mais representam do que um Ciclo na direcão fatal. A soma total do aproveitamento dos recursos naturais não está sendo aplicada no bem-estar da Humanidade e sim visando a destruição de uma parte. O que verificamos, pois, é que, enquanto as necessidades aumentam numa progressão geométrica, os recursos estão sendo utilizados em uma forma aritmética.

Contudo, os tempos se transformaram. Predominam hoje as místicas ideológicas e sòmente elas levarão o homem a conformar - se, dentro de certos limites, na desigualdade que os aflige. Como não podia deixar de ser, o indivíduo dá pouco valor a liberdade desde que não seja acompanhada daqueles requisitos minimos de vivência e satisfações sentimentais ligadas ao instinto 
gerador e a conservação da vida. A filosofia, que gerou a doutrina democrática, ela é pura, perfeita e autêntica, identificada perfeitamente com a mística cristã. Tem sido deformada na sua substância e apregoada como bandeira para o benefício de poucos e o sacrifício de muitos. Tendo como fundamento a "liberdade de idéias e de pensamento", a democracia de nosso tempo condiciona a posse da propriedade a sua boa utilização social. O que vemos contudo é a utilização da propriedade e, em conseqüuencia, do poder econômico em benefício de poucos, relegando a plano secundário o interêsse mínimo de muitos.

$\mathrm{Na}$ democracia autêntica e nos ensinamentos da economia politica do século encontraremos meios, técnica e métodos para encaminhar a Economia no bem comum. Ocupariam o primeiro plano a atenção pelos fatôres de geração e reprodução, saúde e especificamente nutrição, Educação e especialmente a Educação Escolar. Corrigiriamos assim os valôres prevalentes ao máximo das possibilidades da Razão Humana, encaminharíamos o corpo humano para outros esforços de valorização dentro do conceito social, proporcionariamos recursos específicos e adequados para maior e melhor utilização dos bens naturais, chegando, enfim, a uma soma razoável de qualificação humana: Tendo a seu dispor oportunidades iguais, estaria o gênero humano apto a aceitar a convenção de desigualdade, dentro de conquistas minimas, que possam ser consideradas como dignas entre semelhantes racionais.

Como excepcional conquista humana é preciso conseguir-se a mudança do conceito acêrca do trabalho. Cumpridos os principios de justiça social enumerados acima, a transformação da idéia de obrigação para um cumprimento de dever como comparsa de uma responsabilidade coletiva, levaria o homem a empenhar um maior e melhor esfôrço na sua tarefa social. Vemos aqui a dificuldade de encontrar e destinar "o trabalho exato, para o homem adequado e no momento oportuno", obtendo a sua solidariedade para inclinar-se ao interêsse social ao invés de seu próprio, caso haja profunda distonia de ambos. E' lógico que tal alternativa se faça e se compreenda, tanto no conceito de dever que devemos outorgar ao trabalho como aquêle da justiça de dar a mesma
oportunidade a todos.

Passando em revista, assim, ao conceito e à fundamentação do que seja valorização humana, fácil será vincular esta, estreitamente, ao sentido cultural como fator global e total a ser incorporado ao indivíduo. Definindo a cultura: "um conjunto de realizações e estado de consciência próprios que mais aproximam um povo da meta de suas aspirações e objetivos", poderemos entender como
valorização do homem: "a participação de maior número, senão 
de todos, no fruto da evolução cultural dos grupos sociais e da Humanidade, conforme a capacitação de cada qual dentro dos principios da justiça social e especialmente da mesma oportunidade para todos".

\section{CONCEITO GERAL E SOCIAL FRENTE À LIBERDADE DO INDIVÍDUO}

Em principio o homem se valoriza ao poder compreender a dignidade de viver. Contudo, o viver bem tem as mesmas concepções ligadas ao que se compreende e sente por felicidade. Cada qual se integra na sua própria atitude do que seja viver bem. Decorre de tal raciocínio que existe uma discrepância indisfarçável no conceito de valorização humana individual e aquela que a sociedade deseja. A Segurança Nacional levaria a um número de restrições na atuação e na atitude individual visando o bem comum e o resguardo e defesa da cultura do grupo. Contudo um certo número de fatôres tem que entrar decididamente na concepção individual para que a soma dêles concorra para média útil e indispensável. Certas condições prevalentes de valorização. sobretudo no que tange ao fator orgânico, capacita ao indivíduo a aceitação dos princípios convencionais de viver que encaminham a doutrina da liberdade, tornando-o capaz de utilizá-la sem licen ciosidade. Ainda na convenção de viver dentro dos fundamentos da liberdade de idéias e de pensamento, atendido o imperativo da correção dos fatôres prevalentes de valorização e algumas na vigência da idade da Razão e daquela da determinação, é preciso capacitar o indivíduo para escolher bem aquêles que irão executar a sua Política de Segurança. Nas condições acima, a liberdade deve ser fator inerente ao sentido de valorização individual, devendo ser a todo preço incorporado ao patrimônio individual. Sòmente a convenção, também livre, poderá tolher a sua manifestação parcial visando o bem coletivo ou o fim a que se queira atingir na valorização humana. No raciocinio simples, poderemos dizer um Estado, encarnando uma delegação jurídica de um grupo social, é formado da soma do valor dos sêres que o constituem. Em verdade deverá ser o Estado o escravo do indivíduo e constituido para servi-lo. Quando êle tolhe os homens, tornando-os instrumentos dóceis em suas mãos, mesmo com a melhor das finalidades, constataremos que com homens pequenos nada de grande se poderá realizar. O valor do homem cresce com a liberdade que se the pode conceder de empreender, livre e inteligentemente a multiplicidade de relações diferentes que lhes despertem o interêsse e a vontade de participar nos grupos que o cercam ou em sua comunidade. Vemos assim, que alguma coisa antes precisa ser estabelecida como fundamento prevalente 
de valorização para em concomitância outorgar ao indivíduo a liberdade. Esta implica de um lado em um senso de responsabilidade ao exercê-lo, e de outro a convenção de atender a um requisito mínimo de moral ditado pelo respeito às leis. Ressaltamos, pois, na luta pela qualificação humana, criar condições necessárias e indispensáveis, algumas anotadas como valorização prevalente, para encaminhar o individuo social a aceitar convenções que o levem a utilizar bem a liberdade e gozá-la sem distorcer ou deformar o sistema de garantia coletiva na conservação e na evolução cultural. Dentro das restrições convencionais mencionadas, a natureza humana não pode encarar qualquer sentido de valorização que se acompanhe de coação mental, que não se coaduna com a própria constituição e a boa conformação espiritual do gênero humano. As sociedades humanas, que não dispuserem de senso critico livremente exposto de seus cidadãos, não terão possibilidades de evolução. Eis outro fim específico de valorizar o gênero humano proporcionar-lhe condições de estar capacitado a gozar de certa independência econômica, tornando-se útil e necessário a ponto de situar $\sim$ se em uma posição social apreciável ao grupo.

A transformação trazida áo mundo pela industrialização provocou o fenômeno da "massificação" bem estigmatizado por outro lado, a técnica de informações e de comunicações trouxe um maior sentido de penetração e verdadeiro impacto cultural com o cortejo imenso de atitudes reivindicatórias de povos $€$ nações. A reivindicação mais violenta tem $\sim$ se feito sentir no plano cultural havendo como que uma imposição para o acesso mais fácil e maior aos benefícios da educação. Contudo, esta em sua evolução passa por uma fase intermediária que pode levar os povos, grupos e Nações a ações mais violentas e decisivas, chegando mesmo a abdicar temporária ou inconscientemente dos benefícios da liberdade de idéias e de pensamento. Acompanhando as reivindicações, e a elas estreitamente ligadas, encontra-se a abjurada propriedade privada e de riqueza em poucas mãos, incriminadas de retardar a satisfação de uma maioria que também tem direito aos benefícios do progresso.

Não poderemos realmente falar em personalidade, complemento fundamental da liberdade de idéias e de pensamento, e, como estas, atributo indispensável ao cidadão no conceito de valorização, sem que a mesma oportunidade seja dispensada a todos, especialmente na idade da determinação. E' nesta idade que a
educação. na fase média de sua evolução, apresenta os grandes
perigos para o homem. perigos para o homem. Uma massa e uma coletividade é inorgânica e pouco consciente em suas manifestações e atitudes, ha- 
vendo imperiosa necessidade de ser dada autenticidade à liderança dos povos. Um lider apresenta qualidades intrinsecas e êle não poderá ser formado. Contudo a sua influência sôbre uma parcela de opinião pública exigiria legitimidade em sua atuação. Contudo, seguiu a Humanidade as idéias de ArIstóteles contrárias àquelas de seu Mestre Platão. Aquêle considerava mais importantes os individuos, pois que, nasciam, sofriam, trabalhavam e morriam. Êste, porém, outorgava muito acertadamente a maior importância ao homem, dizendo que êste se perpetuava pelos milênios fora. Vemos, pois, o mundo seguindo a filosofia sensorial ou dos sentidos e sendo, na aparência coletiva, era profundamente individual, porque expunha mais os homens aos apetites da ambição desmedida e aos impulsos do egoísmo, quociente negativo passivel de redução ou eliminação. Contudo, a filosofia, do individuo viria ainda mais acirrá-la ao invés de combatê-la. Trouxe imensos malefícios à humanidade, neste ponto, as idéias de ARIstóteles. Sentiriam os homens a necessidade de "promoções de individualismo", perdendo e deixando marginais os sentidos humanos de personalidade. Ora, o romancista e o escritor procurando modificar e alterar o próprio pensamento e as idéias para "conseguir sucesso" na opinião pública. Ora, os políticos, lideres inautênticos, procurando popularidade ao definir-se por idéias e pensamentos preconcebidos para afinar-se com aquêles da massa e da coletividade, sempre levada a atitudes e procedimentos oriundos de emoções, fatos e acontecimentos, não apresentando perfeita organicidade em suas decisões. Já a definição de opinião pública «inclinação para a verdade de um fato sem possuir contudo os elementos subjetivos e objetivos de certeza. Imprevistos, fatos emocionais, ocorrências sentimentais mudam ràpidamente a iterativa então seguida"; tudo isso nos mostra a pouca consistência das opiniões coletivas. A Liderança é uma Arte e não técnica como é o caso de Chefia. Nós poderemos criar Chefes mas nunca criaremos Lideres. Nunca a Humanidade estêve tão pobre de rem-se aos requisitos de Chefia adquirindo técnica, e incarnarem-se no papel exato que lhes cabe de "guiadores de homens", orietando e ampliando por ação de "personalidade" a sua esfera de influência, êles é que são guiados. O escritor e o jornalista de hoje procuram mais na influência social, das tardes de autógrafos, festas, comemorações públicas, a sua "promoção pessoal" do que seguindo real e legitimamente a Arte. Esta exige recolhimento, isolamento, ginástica do pensamento, leitura para amadurecer a cultura própria que se consubstanciará na exposição de seu pensamento e de suas idéias. São citados em pequeno número os grandes escritores e romancistas de hoje que não se 
entregam a uma intensa vida social de "promoção individual". Esta faz parte integrante do cientista, do escritor, do romancista, do político e dos lideres. Clóvis Bevir.aQua um expoente universal das letras juridicas do país, levou uma vida avêssa a atrativos sociais. HEMINGWAY, o grande romancista, vive isolado nas praias cubanas. O que escrevem é autêntico como a própria personalidade, dado que não existem "promoções individuais". São lideres verdadeiros porque transmitem o próprio pensamento sem sujeitarem êstes aos movimentos de opinião pública. Vemos, pois, que o mundo de hoje está sem lideres genuinos. Foi seguido o individualismo de Aristóteles. Todos reclamam que a mente humana não se encontra preparada para utilizar a máquina que inventou e aperfeiçoou. Seguindo a filosofia sensorial, ela está sendo preparada e aperfeiçoada para o bem estar do homem. Simbòlicamente, quando a luta contra a Natureza traz o progresso, a máquina dos homens é utilizada para voltar ao Ciclo da harmonia com o Meio, fim último a que os filósofos antigos destinavam os homens. A luta do animal irracional pela sobrevivência é um dos requisitos do ciclo de equilibrio do mundo. Tôdas as lutas terriveis dos homens não são pròpriamente pela existência e, sim, pela conservação do bem-estar de alguns. Invertem-se, assim, em jôgo de pensamento as posições dos animais.

As despesas das duas últimas guerras se aplicadas na agricultura racionalizada já bastariam para eliminar a fome da face de Terra. Todo o fruto do trabalho a seguir - se seria para ampliar os benefícios do bem-estar. Longe disso nos encontramos ao persistirmos na filosofia sensorial, acenando aos homens com vantagens e ideologias variadas, tôdas mascaradas de místicas, sem contudo atender aos homens nas suas necessidades fundamentais de valorização humana. Antes de cuidar da fome, nenhuma convenção nos poderá facilitar a tarefa de conseguir dos homens, por persuasão ou sugestão, a convenção de conformar-se com a justiça de ter e fazer o que lhe competir. Com fome e sem conveniente resguardo da prole e da sobrevivência, nenhum individuo se atém nas vantagens da liberdade de idéias e de pensamento, nem procurará ter atitudes dë personalidade, dado que o mundo todo faz "promoşões individuais". Não grande coisa se poderá conseguir para a Humanidade com homens pequenos. Nunca qualquer fase da evolução histórica nos colocou na determinação de dispor na Liderança de autênticos valôres humanos. Urge a seleção dos verdadeiros valôres de qualificação orgânica em quaisquer camadas sociais em que encontrem para que guiem os povos para melhores destinos induzindo-os a for-
mar um Mundo Só. 
Em verdade o individuo de hoje é um escravo de sua ambição desmedida a cujo serviço coloca o egoismo exacerbado. Formando na massa inorgânica o de mentalidade escorregadia com atitudes e posições falsamente estabelecidas e movidas por emoções e fatos mal interpretados, age também sem discern mento, sem rumo, sem Razão e muitas vêzes contra os próprios objetivos que defende. Queima bondes e trens pela falta dos mesmos. Julga precipitadamente seus lideres de um momento por um ato e palavras que nunca praticaram ou pronunciaram. Assim, a falta de cultura geral colocou o homem de classe média e mesmo aquêle das elites na posição de modesto operário. O cientista só conhece profundamente a sua especialidade, aperfe çoada para a conservação e melhoria do bem-estar, desconhecendo todos os demais problemas comuns do homem. Ele é "homem massa", e a sua posição de Lider autêntico está vaga. A coletividade, o povo, a "massa humana" está entregue a si própria, ao seu rac ocinio instável, a suas atividades vacilantes, a seus impulsos desorde-
nados.

Com o "encolhimento" do mundo pela rapidez dos transportes e comunicações, houve uma tendência violenta de "sincretização" cultural. Ativou-se e agigantou-se o fato após as duas últimas guerras mundiais. Todo o mundo pode hoje presenciar a vida e o bem-estar de povos e Nações. A finalidade de valorização humana é distribuir ao maior número uma maior parte das conquistas do bem-estar. Infelizmente, porém, alguns requisitos prevalentes de valorização precisam ser atendidos, sobretudo as condições de sobrevivência, melhores recursos para geração, bens de nutrição e, enfim, ensinar a trabalhar bem e a se informar bem. Sòmente após isto será possivel condicionar ao ser social um padrão mínimo de moral que facilite a vida comum, atributos de liberdade que dignifiquem e elementos de certa autonomia econômica que possam transformá-lo sucessivamente em indivíduo,
cidadão e personalidade.

Eis, pois, os três degraus que são determinantes para a valorização global do homem:

a) o individuo necessita ter condições de vida para boa constituição biológica da geração, de sobrevivência e de aceitação com aproveitamento dos métodos e técnicas de valorização;

b) recebendo elementos para conseguir informações, assimilando a cultura prevalente do grupo social, diversificando e ampliando as suas relações com outros homens já pode utilizar a liberdade e mesmo utilizá-la bem tornou-se um cidadão;

c) enfim, com a independência econômica nos têrmos sociais em que é conceituada, pelos meios e técnicas adquiridos 
anteriormente, já pode por si transmitir ao grupo social as próprias idéias e com o resultado do exercício do pensamento fazer evoluir a cultura do grupo - adquirir personalidade.

Não poderemos arrefecer as atitudes e procedimentos de natureza individual em choque ou discordantes da ação social para valorização humana, conseguindo, outrossim, anuência e concordância nas restrições e mesmo coação individual desde que não possamos integrar a pessoa na sua própria caracteristica de animal racional. A fôrça do instinto predomina sempre dado que a sobrevivência está em jôgo. Ora, justamente uma série de fatôres de valorização para serem incorporados exigem a abstração de problemas fundamentais de conservação e evolução orgânica. A sociedade sente a necessidade de que o homem domine e discipline o instinto, contudo êste está integrado intimamente na conformação biológica. No homem social respeita-se e tolera-se um limiar de atitudes e procedimentos instintivos, levando a Lei que regula um mínimo de Moral, a respeitá-los. O direito de matar em defesa própria é sagrado e consignado em tôdas as leis humanas. Assim, a sociedade consigna um direito individual e nega o direito coletivo de procedimento e atitudes referentes à conservação da vida pelo direito de acesso aos bens de nutrição, argumentando com o direito de propriedade, ela mesmo condicionada no regime democrático - ao bem comum.

Com a predominância do sentido sensorial da vida sôbre os atributos espirituais e subjetivos de excelso valor, qual seja a liberdade de idéias e de pensamento, muito trabalho será necessário para persuadir e sugerir aos homens de que a valorizaçâo global e total exige uma perfeita integração. Tal sublimará e disciplinará as ações instintivas e aperfeiçoará a elite, e mesmo o cidadão, na senda do refinamento da Moral, isto é, da Ética, decorre logo que o exemplo, o melhor impulso educacional, é obrigação dos chefes, e, como é óbvio, dos lideres autênticos.

Eis, pois, que, ao pensarmos em valorizar o gênero humano. se impõe a Educação que procura incutir principios fundamentais de valorização social, sublimando a sociedade a Politica e a Ética, disciplinando a inteligência, assegurando o bem-estar, enaltecendo a virtude, humanizando o instinto, garantindo a evolução criadora, divinizando a continuidade da espécie e firmando o conceito de justiça de - cada um ter e fazer o que lhe compete. Contudo, no uso da Razão e na responsabilidade da determinação, tem o homem que resguardar os atributos espirituais, situando nestes a predominância de viver. A personalidade integrada na sua função, que caracteriza o grande homem, resultará na formação da grande Nação e na substituição do simples progresso pela $\mathrm{Ci}$ -
vilização. 


\section{A EVOLUÇÃo CULTURAL COMO FINALIDADE DE VALORIZAÇÃo}

A cultura real que identifica uma Civilização e que apresenta características livres de crítica para evoluir está sèriamente comprometida no momento presente. Estamos criando um surto de progresso excepcional penetrando sitios há pouco inacessiveis à Razão Humana. Confundimos lamentàvelmente a cultura global, envolvendo as aquisições de valôres espirituais e mentais com aquela estritamente dirigida à satisfação dos sentidos. Se o caminho persegu:do pela Humanidade é conseguir para o gênero humano uma convenção satisfatória de um conceito de Felicidade, vemos que a Cultura encarada em parte nunca poderia atingir a sua finalidade. Os homens de inteligência do passado resguardavam o pensamento de influências subalternas e imediatistas. Hoje vemos o carreirismo, a aventura, a popularidade e o materialismo deformando inteiramente o pensamento e a ação dos lideres do pensamento humano. A idéia de escrever e propugnar pela elevação global do homem ampliando o campo de seu patrimônio espiritual e moral deu lugar a uma ação de concessões, contrafações e mistificações consentidas e toleradas. Procura-se expor idéias e pensamentos que possam conquistar prestígio politico e social, especialmente mundano. Tais condutas facilitam a aquisição de titulos e honras acadêmicas, propiciam negócios e farturas. A literatura e o romance da época falham profundamente como verdade essencial e como substrato de espírito criador que pudesse acompanhar a originalidade e a técnica dos mecanismos destinados a satisfações instintivas, inteiramente outras que não aquelas de prevalência de valor visando o organismo e a máquina humana. Lutam os homens pelo acesso ao supérfluo e aos processos de ostentação.

$\mathrm{Na}$ ordem de valôres a nossa cultura tem colocado em lugar precário as aquisições do espírito. A sociedade dispensa uma falsa atenção a atividades inautênticas que se revestem de colaboração positiva de "promoção" de situações e condições materiais mais avançadas. Vemos obras históricas serem avaliadas nos museus em moeda corrente, mesmo aquelas de simples usos pessoais de grandes vultos. Aquêle grande valor não conversivel, não palpável, não passivel de transformação em bens sensoriais. é classificado em plano inferior. O que defendemos para o homem superior é a convicção consciente despida de injunções e influências subalternas. A isto chamamos "personalidade", estágio superior de valorização indispensável a uma evolução cultural determinada e determinante para a integração do valor humano. Justamente neste ponto está nosso ciclo de progresso humano falhando desastradamente. 
Vamos encontrar na disputa de Platão e Aristóteles, há 2.300 anos, a causa predominante dos rumos deformados da atividade do gênero humano na construção de uma verdadeira $\mathrm{Ci}$ vilização. Dando maior importância ao estudo do "homem" demonstrava PLATÃo a necessidade de englobar a mente e o pensamento nas pesquisas e análises. Aristóteles propugnava e dizia que os "homens" por nascerem, sentirem, sofrerem e morrerem deveriam merecer a maior atenção. Descambou o mundo, e justamente as Nações lideres do progresso universal de hoje, para a trilha da filosofia sensorial, aguçando os fatôres negativos do crganismo humano como o egoísmo, ambição exagerada, amor aos prazeres instintivos e o estímulo à inveja. Seguissem o outro caminho e seria utilizada a Cultura no benefício do "homem" e não para satisfação de alguns "homens". Todos lastimam que a máquina cam nhou adiante de uma mente humana e Razão incapazes de controlá-la. Razão e mente humanas capazes de controlá-la, discipliná-la, encaminhá-la e destiná-la ao bem comum, como fundamental à Civilização. Vemos, pois, que os Grupos humanos divergem e util zam a máquina para resguardar, não as conquistas espirituais e morais, mas as satisfações instintivas, secundárias e degeneradas. Outra fôsse a conduta e as satisfações minimas da natureza humana seriam prontamente preservadas como fundamento mesmo da evolução cultural. Nenhum processo, nenhuma cultura, nenhuma pretensa Civilização poderá jatar-se de ter completado uma obra satisfatória quando alg̣um representante do gênero humano se debate na luta pela conservacão da vida e da geração, como fator prevalente de valor individual.

A confusão, que se estabeleceu na luta dos dois grandes filósofos, resultou na deformação da semântica flosófica do "Objetivo" e do "Subietivo". Eis a premissa hásica dos procedimentos humanos que falsamente denomina Cultura a uma integração parcial de valôres, a uma satisfação instintiva primária e a uma abstenção dos atributos contidos na personalidade. Os grandes homens de hoje deixam perceber a mediocridade quando disputam em atos e manifestacões os favores exteriores em beneficio de seu individualismo. Tudo hoje é promoção individual e despista-se um Lider pela facilidade e certeza com que sabe definir, não as próprias idéias e o próprio pensamento, mas a idéia e o pensamento coletivo, inorgânico, infiel, flexivel, maleável e transitório. Não é o Lider que transmite e, sim, o que define o"que a platéia quer pensar. Ela que teria responsabilidade de guiar e orientar, pensa e aqe na satisfação individual de ampliar o seu prestígio social, político e econômico. Cuida apenas de "promoção". Os meios de informações estão todos comprometidos, não 
com correntes autênticas e personalisticas de pensamento, e, sim, com opin ões e interêsses de grupos e facções, dogmas científicos e religiosos, sempre endereçados a conquista de posições e situações.

A atual Civilização seguindo ArIstóteles no particular da disputa mencionada, relegou a plano secundário o problema humano, atendo-se apenas a atividades de "sujeito" quando considerava "objetivas", não o sentido da verdade real e autêntica, que é a idéia de esfôrço no sentido da valorização de gênero humano. Renouvier na reformulação de princípios filosóficos, conceitua como objetivo" apenas a idéia que é o que se oferece como objetivo representado na consciência. $\mathrm{Na}$ mesma corrente se colocam Bergson, Parodi, Paui. Dupont. $\left({ }^{*}\right) \mathrm{O}$ trabalho, a pesquisa cientifica, a atividade e o esfôrço muscular constituem aşões "subjetivas", porque o "objetivo" é a idéia e esta deveria ser a elevação cada vez mais da dignidade humana. A única coisa "real e objetiva" é exatamente a idéia e o pensamento voltados decididamente para a difusão e acesso dos bens e vanta gens da cultura ao maior número. Assim descreve Bucken o seu interêsse em reformular principios da Filosofia. $\left({ }^{\star \star}\right)$ Em linguagem acessivel na atividade do sujeito, diriamos que o comerciante deveria ter no preâmbulo de suas atividades "subjetivas", a idéia de distribuir o melhor e em maior volume e condições favoráveis as suas mercadorias, tendo uma finalidade subjetiva de ganhar dinheiro. A isto chamariam a Ética profissional. Contudo, pouca gente utiliza a ética nas suas relações sociais se bem que clamem constantemente em seu nome.

A falta de conhecimento de homem, se bem que se alardeie as vantagens e a necessidade de humanismo, coloca a humanidade à mercê das técnicas e especializações científicas, visando à tilosofia sensorial, a ponto de os povos se verem na fase de suas reivindicações sociais e humanizantes, sem lideres autênticos que os quie. Deu o alarma Ortega y Gasset, tanto na sua correspondência aos jornais de Paris em 1938 como pela publicação de seu livro "Rebelião das Massas". O técnico de alto nivel e o cientista são situados hoje em igualdade de condições no que respeita ao conhecimento dos problemas humanos. Assim, os atributos de personalidade que deveriam caber às elites, Chefes e

(*) Renouvier - Essais de Crit. Gen. Logique, I, pág. 19.

BERGSON - Matiére et Memoire.

PARODI - La philosophie contemporaine en France.

Paui. Dupont - Les Problèmes de la Philosophie.

(**) BuckeN - Gesch. der Phil. Terminologie, pág. 68. 
Políticos, vêm encontrá-los como atôres na luta de competição no que se refere a "promoção de prestigio e conquista de bens". Eles, que deveriam incutir a determinação de difundir e dar acesso da cultura a um maior número, procuram justamente juntar nas próprias mãos, para seu gôzo e satisfação, as benesses cujas origens e fundamentos foram entregues ao homem. Reportando-nos aos interêsses de um grupo social, no seu esfôrço em decisão de evoluir e progredir, é necessário e imperativo que caiba ao maior número possivel os benefícios de desenvolvimento e de evolução, dentro da justiça de outorgar a mesma oportunidade a todos. Corsseguido êste resultado, caminhariamos progressivamente. no sistema convencional de viver e na implantação de uma mistica indispensável a uma coletividade que se sujeita a sacrifícios e penas na esperança de situações e condições melhores.

\section{FUNDAMENTOS E FATÔRES}

A deficiente garantia da Segurança de Grupos sociais para resguardar e defender a própria Cultura, decorre justamente de não terem sido aplicados os recursos e valôres incorporados nara - "objetivo" de dar acesso e propiciar condições indispensáveis e recursos espirituais e materiais de valorização do homem a um maior número, continua e progressivamente. Assim, alguma parte do esfôrço e dos valôres mencionados são destinados ociosamente a construir máquinas de destruição do próprio homem. Contudo, tal procedimento, tem em vista o caminho percorrido dentro de uma falsa filosofia de vida, enaltecendo e dispensando atenções maiores aos assuntos de matéria do que da parte realmente nobre da natureza humana: Razão e Espirito. Seguisse a Humanidade outros rumos na perseguição decidida de divulgar o mais possivel as vantagens da Cultura, não haveria porque desviar uma parte do esfôrço e dos valôres visando defender grupos sociais em uso e gôzo de parte dos bens ao alcance e do direito de todos.

O Ciclo presente da Humanidade nos induz como alternativa a identificar grupos antagônicos, havendo a necessidade, ao ponto histórico que focalizamos, de jogar com o-esfôrço conjugado e coletivo para defender as conquistas adquiridas. Preparamos os homens do grupo social para a hipótese de estar em perigo o acervo cultural já incorporado. Quando acenamos com o amor à Pátria estamos induzindo e sugerindo o esfôrço coletivo tendo em vista tal finalidade. Aliás, a constituição humana é colocada nas contradições e lutas. A própria vida resulta de antagonismos e desequilibrios sustentadores da evolução biológica. Não poderia, portanto, esta semente enraizada de antagonismos e lutas ser combatida ou alterada por transformações e modificações sociais 
decorrentes da luta do homem contra a natureza para construir seu progresso e sua Civilização. As maiores deformações hoje assim consideradas acêrca do procedimento dos homens, têm traLido inestimáveis valôres positivos para o homem. A era economica liberal produziu extraordinários frutos para o gênero humano. Baseava em uma aparente injustiça social a sua atividade, dado que disputava com proporções vantajosas a posse da riqueza. Não é por outro modo que a filosofia pode identificar o bem através da existência do mal. Só pode haver melhoria e evolução tendo em foco sempre a insatisfação. Esta gera ambição, difícil de ser controlada ou disciplinada. O egoísmo é parte integrante da natureza humana. Até que ponto poderemos sofreá-lo em um sentido educacional não o sabemos. Uma coisa precisa ficar bem esclarecida. A correção dos fatôres negativos de qualificação individual e coletiva necessitam precipuamente de um estado hígido mais satisfatório possivel. $U$ instinto, caracrística fundamental do gênero humano, tem na sua disciplinação e socialização a tarefa mais importante da Educação. A Razão, fruto da constituição biológica, é atributo determinante da ação educacional. Se bem que todos os homens sejam racionais, nem todos apresentam a mesma capacitação mental, onde um conjunto de condições localiza o indivíduo em sua posição social e sobretudo na sua atuação no grupo. O assunto é tão controvertido e discutivel que os gênios que tantas e importantes contribuições trouxeram à Humanidade, pela exacerbação de setores de qualificação mental, apresentavam no exame total e global condições vizinhas daquelas insociáveis. Grandes vultos do passado eram caracterizados por extravagância, palavra modesta para significar autênticas marginalidades sociais.

Assim, pois, no desejo de valorizar o homem, precisamos de qualificação minima de possibilidades orgânicas da formação da Razão. Esta é que facilita a adaptação do ente humano ao meio social em causa nos primeiros contatos e nas primeiras tentativas. Seguem-se as ações orientadas no sentido da experiência, a partir dos meios suficientes de informar - se com que adquire a situação de cidadão, onde passa a compreender os deveres, já uma forma de coação convencionalmente consentida. A má formação da Razão torna esta fase excepcionalmente dificil. Concluimos assim que o cuidado na geração, a formação e a constituição orgânicas, são fatôres primários, primordiais e fundamentais da valorização humana.

Não se pode, pois, conseguir os melhores e maiores resultados das ações, táticas e planos destinados a qualificação necessária e indispensável de homem para a evolução cultural do grupo, sem que se possa dispor de condições biológicas favorá- 
veis. Contudo, na formação da família, os elementos geradores, que ultrapassaram bem ou mal o limiar da Razão, precisam colaborar e consentir na assistência a que não estejam suficientemente habilitados. Resulta disso que dificilmente poderemos estabelecer hierarquia entre a Saúde e a Educação, devendo os dois processos assistenciais estarem profundamente solidarizados e entrosados.

Não poderemos falar em desenvolvimento e evolução sem que dos mesmos participe o homem na posse dos requisitos suficientes de cultura, consubstanciados na qualificação global. Se a mão manipular a máquina, a sua função é guiada pelo cérebro e por êste estabelecidos os requisitos necessários aos deveres e a iniciativa indispensável para compreender os direitos. Em se outorgando a mesma oportunidade satisfazendo certas minimas sensações instintivas, atendidos certos requisitos sentimentais naturais, resguardada a securidade familiar e pessoal nos imprevistos e acontecimentos, só poderemos conceber um cérebro disposto a atender dentro da Razão e da determinação ao cumprimento do
Dever de produzir.

A taxa demográfica inquietante, que atinge o mundo e especialmente o Brasil, exige que cada homem produzindo terá que fazê-lo para muitos outros homens e para aperfeiçoar e adquirir outros instrumentos e máquinas de produção. Para tal objetividade a Educação Média facilita no sentido horizontal como conseguir melhores e maiores resultados das máquinas e dos instrumentos. Cada indivíduo necessita produzir cada vez mais e sòmente a produtividade permitirá sobras favoráveis para atender a fatôres e valorização de outros sêres e a compra e aperfeiçoa-
mento de outras máquinas.

Fazendo mira no "objetivo" de distribuir ao maior número uma quantidade sempre crescente de bens de uso e de consumo, propiciando as vantagens e prerrogativas da Cultura ao maior número, sòmente a Escola poderá fazê-lo pela Ciência, Técnica e Organização, conjugação que pode prover e prever, e portanto planejar, quando serão aproveitados ao máximo os recursos disponiveis. E' o único caminho a seguir na luta para o desenvolum diagnóstico a a de situação das condições humanas, como que a serem corrigidas, sempre visan deformações, distorções e atitudes diferente se visando à qualificação humana. Muito qual ficada fôr o primeiro tan do cidadão. Contudo quanto mais tará para integrar-se tanto melhores condições êle apresentendentes a evoluir e napel do segundo e cumprir obrigações dêle. Assim, a Biologia, a Sociologiantia no grupo e fora aquisições mais importantes, embora ainda recentes e com defi- 
cientes delimitações e disciplina. Com estas adquiriram novos rumos a faina de reestruturar melhores fórmulas de vida social e de procedimentos frente ao interêsse do homem. A Matemática, pela Estatística completou o quadro que enriqueceu sobremodo a economia politica, ciência e arte de propiciar bens e melhores condições de vida a um maior número, utilizando os mesmos recursos. Assim, duas categorias importantes do conhecimento e da experiência vieram faciltar a tarefa de atender ao objetivo de qualificar o individuo. O primeiro, pelas ciências citadas, a avaliação prevalente das qualidades de homem e de cidadão e a etiologia dos procedimentos, e o tratamento conveniente. A outra é a Economia Politica, ciência e arte do Estadista, disciplinando e organizando a criação de riqueza para o bem coletivo. A Estatística veio colaborar intensamente com ela resguardando c sentido da média. realmente o melhor critério encontrado para a ação da Cibernética. Com Fayol, Taylor, Wallace Clarck conseguiu-se o aproveitamento pela racionalização de recursos. Anaiisando-se, contudo, os meios e os fins da produção caminharemos muito além, pois que teremos que sublimar o homem levando -o uma integração consciente de si mesmo. Lembramos, porém, que as diversas técn cas procuram melhorar a vida dos homens, valorizá-la, aperfeiçoá-la com a medicina, a engenharia. a politica e o direito. Ora seria considerado parceladamente como animal, ora como consumidor ou criador de riquezas, ora como fração social e cidadão responsável. Advertimos, contudo, que a Educação deverá fazer mu to mais. Reúne tudo aquilo para engrandecer o homem. Integrando na fase da Razão e investido dos deveres e direitos de cidadão, o homem exaltará êle próprio os atributos do espírito, das idéias e do pensamento como o ápice sublime da valorização humana. Eis porque na politica de desenvolvimento e evolução a tarefa continuará sempre tendendo a absorver profundamente e sempre os claros vastos e desconhecidos do pensamento para atingir à perfeição espiritual e ao refinainento moral como satisfação última e acabada.

Sem tal condição de insatisfação, nenhuma categoria de valorização conterá enqlobados todos os recursos potenciais, e jus tamente os mais sublimes do gênero humano. Sendo, pois, a vida, a sintes perfeita da matéria, todos os grandes homens do passado dela se desfizeram pela vitória do espirito, das idéias e do pensamento. A êste resultado chegaremos nas etapas sucessivas, desde a condição primária, individual e instintiva, passando pela compreensão e pelo raciocinio, a um campo infindável amplo, qual seja o aperfeiçoamento do espirito, refinamento do pensamento, oriqinalidade das idéias e novos caminhos a serem percorridos, perseguindo sempre a Verdade. 
Não será possivel entender valorização humana sem conse. guir integrar eficientemente a família como célula social na dinâmica do processo. Assim, serão consideradas as seguintes categ̣orias de estágio do homem para congregar ações e atenções ligadas ao imperativo de valorização global:

a) o individuo - valorização prevalente, instinto;

b) a família - instinto e sentimento, conformação social;

c) o cidadão - moral e civismo. Direitos e deveres;

d) a personalidade - Chefia e Liderança - Educação e Exemplo. Ética.

O indivíduo nunca será complementado na sua formação sem que possua um elo sentimental passivel de incentivá-lo em sublimar a inclinação instintiva. Compete à Sociedade atender ao gênero humano na idade da formação, nas necessidades físicas morais e sentimentais que não estejam à sua disposição. Consideramos uma fase e um período mais ou menos longo de responsabilidade. A capacitação mental limita e disciplina a responsabilidade social, tornandora contudo desobrigada, no que se refere ao sentimento, quando a Razão demonstre aquisições de atributos suficientes de arbitrio, para exigir direitos a vista de cumprimento dos deveres. Aumenta muito a tarefa, da sociedade, dificultando por outro modo a sua atuação, o atendimento deficiente do individuo nas suas sensações inst ntivas de familia e de grupo. Mais tarde na formação do cidadão e da personalidade, maiores ou menores dificuldades correrão da ação eficiente nas fases anteriores. Compete à Sociedade resguardar-se dos males sua evolução.

O conhecimento histórico só tem permitido a consciência das civilizações pregressas a um limite máximo de oito mil anos. A sua autenticidade, porém, tem sido sacrificada pelos interêsses políticos no ponto histórico considerado, distorcendo, e removendo elementos que poderiam dar uma transmissão mais real das culturas passadas. Os dogmatismos religiosos, sobretudo, muito alteraram a filosofia da história, quando transplantada para as gerações que se sequiram. A Arqueologia tem retificado profundamente alguns fatos, atitudes e procedimentos falsamente estabelecidos como verdadeiros. Contudo, os fundamentos básicos do proqresso e da atual Civilização, em suas orirens mais primárias estão firmados na descoberta da roda e na disciplinação genética do cavalo. Contrariando Malraux, achamos que as Civilizações não se extinquem, completamente, alguma coisa resta de continuidade e perpetuidade do processo cultural essencial. O que
podemos afirmar é que, apesar de tudo, o homem se aperfeiçoa. 
Advertimos, porém, que o progresso atual, que denominamos Civilização, ainda permite que sòmente aproximadamente $20 \%$ dos homens tenham acesso aos bens comuns provindos do Potencial Natural que lhes foi confiado. Cêrca de $75 \%$ ainda não conseguiram o acesso a uma conquista minima de bens que os classifiquem na qualidade de gênero humano vivendo na atual Civilização. E' bem verdade que as Ciências destinadas ao estudo do Homem sejam de evolução recente, algumas mesmo ainda não disciplinadas nas suas limitações e responsabilidades. A Matemática, que era cultivada para glória de alguns homens, tornou-se hoje matéria destinada ao bem comum. A Biologia, revelando os segredos, as reações e a evolução orgânica, trouxe subsídios essenciais para reajustar fatôres prevalentes da valorização humana. A sua coordenada especifica a Psicologia, mostra os segredos da mente, na sua análise isolada e na acomodação civica. Enfim, a Sociologia amplia o campo, dando a visão global e total, somando reações particulares e concluindo das resultantes gerais. A conjugação de tudo concorre para capacitar o líder autêntico e equacionar sua linha de ação objetivando a coletividade, organizando o conjunto, capacitando o particular e aparelhando o cérebro para ação muscular. É a Cibernética. Por outro lado, a ciência e a técnica de comunicação forçou a entrega mais autêntica do Real Poder Politico nas mãos do povo, levando êste a impor a satisfação de suas minimas necessidades e a bater-se pela qualificação civica.

Acreditamos que na revolução social atual SpENCER não seria levado a comparar a história das Nações como aquela dos homens. Uma irmandade universal, tendendo ao interêsse humano não desfaleceria. Spengler não diria que os povos "não se estinguem fìsicamente, mas sobrevivem despejados de substância. São troncos eretos na floresta, continuou êle, secos e sem seiva que por séculos e séculos ai permanecem, elevando para os céus os galhos mortos". Hoje vemos a recuperação da India, da China e mesmo o Egito, exemplos contraditórios nas frases chocantes.

Assim, se cada grupo profissional ou social cumprir as determinações éticas da semântica filosófica do "objetivo", disciplinando e explorando bem as qualidades negativas individuais, como o egoísmo e a ambição, não teremos dúvida em afirmar que estará assegurado ao progresso atual o destino de construir uma autêntica Civilização.

\section{QUALIFICAÇ̃̃o HUMANA FRENTE À SEGURANÇA NACIONAL}

Enquanto a Civilização evoluida e aperfeiçoada não congregar os povos e as Nações dentro, porém, dos princípios de justiça social em uma irmandade universal, cada grupo social terá 
que ter sempre viva a alternativa de defender os valôres adquiridos e o direito de acrescentar outros valôres para uso e gôzo de seus cidadãos. Decorre disso, no ponto histórico por que passamos na Humanidade, a obrigação de impor ao cidadâo do grupo utilizar os valôres adquiridos ou imanentes no benefício comum. O Grupo Humano poderá reclamar e lutar pelo potencial disponivel e não aproveitado com os meios conhecidos. em seu beneficio. Com tal raciocinio não existe Defesa Nacional possivel de contrapor-se com sucesso a reivindicações instintivas ainda classificadas no campo individual das necessidades. Sòmente a Segurança Nacional, que é o esfôrço do grupo social em aproveitar o Potencial Natural que lhe coube, inicialmente em conseguir evolução e desenvolvimento em tempo útil, amplia o campo de formação civica e atendendo nas proporções devidas a suas obrigações, a valorização do Homem. Para atender ao sentido de maior aproveitamento do Potencial há que conjugar Homem e Meio.

A maior aspiração de uma Nação é possuir terra, em amplitude e qualidade que permita conter riquezas e Potencial para que sua população encontre meios primários e instintivos inerentes a fatôres prevalentes de valorização. Quando existe a Terra, tornou-se a Nação um País. Contudo, na convivência da irmandade universal, convencionando regras e conciliando interêsses, atendendo a deveres e gozando privilégios, haverá o imperativo de disciplinar o Direito, tanto o dos individuos como aquêle das coletividades, tornando-se à sociedade capaz de sintetizar no Estado o cumprimento de tais atribuições que culminam com a Soberania. Não basta, contudo, que possua terra e população, tem obrigação humana de fazer evoluir a Cultura e ajudar a construir a Civilização histórica. A Cultura está sujeita a trocas, intercâmbio, intromissão ou transm'ssão, com que procurará erguer o prestígio universal acenando com a fôrça moral de ter duos como ter elevado mes instintivos mínimos de seus indiviintegrar a uma população de cidadãou esforçco de valorização a da técnica de comun cacões o mundo Hoje pelo aperfeiçoamento analisa e muitas vêzes critis o mundo inteiro nos observa, nos antigamente caso isolado e efetivo intromissão de cultura, que era paganda de idéias e de pensamento ra ação, atua hoje pela procões e a atitude socia:s e politica resultando-em perigosas realeiro exige a determia's e políticas. O imenso Potencial Brasiuma mistica decisiva pela de seus habitantes para estabelecer da. Segurança Naciona pela difusão cultural. Torna-se imperativo cia, e a Técnica e a Organizacãoção humana. dado que a Ciênprocura prover e prever a utilizacintetizam o Planejamento. Este- 
níveis, conseguindo o seu máximo aproveitamento. $E^{\prime}$ tal o recurso hoje existente que a idéia de que as necess dades progridem em ordem geométrica e os meios em ordem aritmética tornou-se inteiramente falsa. Pois bem, a conceituação exata de Segurança Nacional é justamente obter as melhores informações das condições e situações existentes, congregar os recursos e meios visando, dentro da melhor provisão e previsão a conquista de novos meios e novos recursos, sempre acima das necessidades coletivas, obtendo novos valôres que constantemente avaliados encarnam o Poder Nacional. A demografia, que é fundamento dêste, está contudo subordinada a uma série de fatôres qualificativos. Alguns ligados ao indivíduo, outros ao sistema de viver, alguns à forma de estrutura social, e mu tos a questões básicas de aspirações e objetivos comuns que ditam a politica, conseqüência muitas vêzes da tradição do caráter. Tem assim importância quant’s à população: o volume, a densidade, a distribuição, a estrutura social, a fôrça de trabalho e a qualificação global onde se firmam questões básicas na unidade de pensamento, na preservação da cultura, nas aspirações a serem perseguidas e nos objetivos a serem alcançados.

\section{POLÍTICA DE VALORIZAÇÃo HUMANA PARA O BRASIL EQUACIONA-} MENTO PARA O CONCEITO DE VALORIZAÇÃo

Dentro das idéias expostas poderemos verificar que o Potencial humano brasileiro ao invés de constituir uma fonte de Poder Nacional está gradativamente se tornando um fator negativo do mesmo. Logo, no sentido de prioridade, colocaremos a satisfação dos mais primários requisitos de valorização prevalente como aquêle que deverá despertar a atenção no que respeita aos interêsses da Segurança Nacional. Os meios e recursos existem. dispersos, pulverizados e ociosos, atendendo a uma parcela pequena de suas possibilidades. Em um regime ideal de viver qual seja a convenção de liberdade. deveria ser estabelecida a contrapartida de investir em ordem proaressiva e percentual uma parte diss valôres conquistados anualmente, visando à valorização individual. Por outro lado a falha de racionalização no aproveitamento dos recursos naturais nos levará a resultados imprevisiveis. Já Gifford Pichot em sua obra "Better living through wise use for resources" disse:

"Uma Nação privada da liberdade pode adquiri-la: uma Nação dividida pode unificar-se, mas uma Nação cujos recursos foram destruídos pagará inevitàvelmente com a pobreza, a degradação e a decadência". 
O trato racional da terra, o combate ao esgotamento da terra por métodos técnicos, a educação do agricultor e suas dificuldaóes econômico-financeiras, a ingerência politico-partidária nociva na Política agropecuária e a desordem administrativa - são pontos a serem atendidos com a maior urgência. Havendo possibilidades potenciais para atendimento das necessidades primárias, ainda na formação individual, - sobretudo no campo de atividades onde aliariamos uma parte essencial de Saúde, qual seja a nutrição, as lides agropecuárias são, outrossim, um setor econômico de especial interêsse. Nelas encontramos $67 \%$ da população ativa do país, quase totalmente necessitada dos fatôres primários de valorização humana. À fôrça de trabalho resultante em parca produtividade por má qualificação profissional alia-se a atividade nociva destruindo os recursos naturais ou tornando mais restrita a sua vitalidade. O esfôrço conjugado atendendo a Saúde e a Educação, redundaria em melhores valôres econômicos libertando, outrossim, os braços mais qualificados para as atividades secundárias. Tendo uma enorme superficie de terras agricultáveis, acumulamos com a pior distribuição cêrca de $36 \%$ da população em uma área de $656.241 \mathrm{Qq}$, numa faixa marítima de aproximadamente 100 quilômétros. Com tal excesso de terras arcamos com o grave problema de minifúndio social e funcional em cêrca de $50 \%$ das terras trabalhadas. Decorre logo o racioćinio de iniciarmos colonizações bem dirigidas dissem nando núcleos populacionais bem assistidos que seriam sementes higidas de futuros centros administrativos. Não basta, sendo até nociva, a simples localização física do agricultor.

As Colonizações teriam os requisitos minimos exigidos para a vida do grupo social em causa, tendendo a ascender o nivel de qualificação de indivíduo a cidadão. A energia elétrica doméstica e a canalização de água, possibilitando ao núcleo servir-se dos meios modernos de comunicações e de melhorar a produtividade e aproveitamento dos produtos primários, são exigências indispensáveis na formação de núcleo populacional. Atendendo a requisitos atinentes ao instinto e a informações atenderíamos convencionar a concordância com os demais fatôres de valorização condizentes com o aperfeiçoamento do espirito, elevação dos padrões morais e a utilização favorável da liberdade. Este certo grau de independência econômica refletiria na graça, segundo Santo Agostinho, de escolher bem os homens de liderança. Ressaltamos mais uma vez o imperativo de associar Saúde e Educação. Em uma fase ainda incipiente de recursos energéticos bem difundidos, necessitamos de maior fôrça calórica e de melhores 
condições de esfôrço muscular. Já GEORgE Wythe em seu livro "Brasil, Expanding Economy" disse:

"A Saúde é indubitàvelmente um dos maiores problemas do Brasil de hoje, sendo que em nenhum outro terreno podem tão grandes lucros, ser obtidos com investimentos relativamente tão pequenos".

Eis porque advogamos que o regime democrático trate cuidadosamente de disciplinar quotas percentuais orçamentárias que completem a distribuição de Renda até atingir realmente a 5,5\% para a Educacão Escolar (incluindo Ciência e Técnica) e um mínimo de 3,5\% para o setor Saúde. Os investimentos assistenciais no setor agropecuáro, se bem que com características assistenciais torna-se um investimento de prazo muito mais curto, também com vantagens econômicas imediatas.

Anualmente as estatísticas nos mostrarão os rumos a seguir no que respeita a adaptar os fins aos meios. Nas três faixas de atividades soc'ais: primária, secundária e terciária estará a análise indispensável ao estudo dos resultados. Diminuindo em proporções favoráveis a atividade primária, aumentando sensivelmente a secundária e havendo substancial aumento da terceira, estaremos caminhando corretos na linha que nos conduzirá a grandes destinos como povo e como Nação.

Ao dizermos que a população mundial em cêrca de $75 \%$ encontra-se à margem dos requisitos minimos de valorização do gênero humano, poderemos situar nosso país na faixa de $65 \%$. Menos de $20 \%$ de brasileiros estão aptos a cumprir as obrigações de cidadania tal como a República de Atenas sob a Presi-
dência de Péricles há mais de dois mil anos.

Nas atuais condições de desenvolvimento os orçamentos públicos deverão investir $17,7 \%$ com a Educação Escolar e $8 \%$ com a Saúde. Esta, no que respeita à Higiene Pública seria de total responsabilidade do Estado Federal, deixando a Assistência médica em geral para a sociedade através de colaborações cooperativistas, propiciando-se padrão igual de medicina para todos e conseguindo de cada qual colaborações diferentes de acôrdo com as próprias possibilidades. Tal conduta é seguida nas democracias mais evoluidas de nosso tempo.

$\mathrm{Na}$ Securidade Social é preciso dar aos Institutos a sua verdadeira e real finalidade de atender a necessidades perenes do homem. A doença é uma incidência e deverá estar sob a responsabilidade mista privada e oficial, sob forma de seguro ou de cooperativismo. O Instituto tem que atender precipuamente as aposentadorias, pensões, seguros, acidentes de trabalho e a resi- 
dência higiênica. Como suplementação, sobretudo a melhoria social de instalações já existentes, atenderia à assistência médica em geral.

Erro grave de estrutura existe na Assistência Social no Brasil. Não será possivel continuar sem um processo de unificação da Assistência Médica, organizandorse a Coordenada Hospitalar, onde seriam estabelecidas e disciplinadas as competências de cada unidade. Cada Hospital-Base consciente de sua responsabilidade e atribuições, estendendo-se o mesmo para os Hospitais Distrital, Rural e Postos de Saúde. A discriminação de dependência administrativa, classes, municipais, estaduais e federais, fere profundamente os preceitos universais do aproveitamento racional dos recursos assistenciais, cuja fonte é social e única. Os Organismos de Coordenação não tira à unidade a sua independência, apenas regula competências e atribuições. Temos como certo que aproximadamente $70 \%$ das verbas assistenciais no Brasil constituem investimentos ociosos. O Estado da Guanabara tem cêrca de 8 leitos hospitalares por mil habitantes, um dos indices mais elevados do mundo. Um indice de 4.5 é bastante razoável, tal como se observa nos E.U.A. Pois bem, o Estado citado tem uma péssima assistência médico-hospitalar, planejando sempre a construção de novos leitos. Existe no país cêrca de 25 mil leitos hospitalares sem funcionar e inauqurados, em um total aproximado de $164 \mathrm{mil}$. Reclama-se stmpre pela construção de mais hospitais. Funciona a promocão individual e demaqóqica servindo de bandeira a Saúde. Tal at tude atinqiu os Institutos, entregue a atividades politico-partidárias até há pouco. Nenhtuma contribuicão fixa será capaz de dar um padrão razoável de assistência médica. Eis porque os Institutos não podem cumprir as finalidades precipuas para que foram criados.

Sem atender a requisitos prevalentes de valorização primária e instintiva, não poderemos tornar aceitáve's nem compreensiveis atributos essenciais e globais de valor humano, tal como um padrão mínimo de moral cabivel nas leis e muito menos ensaiar os lideres em tal campo de desordem social e aventura quanto aos requisitos estabelecidos, pela Ética e pela Técnica que o capacitariam para a Liderança autêntica.

A autoridade, responsável pela formação do Estado Democrático, tem que reformular programas e planos de recuperação administrativa que a torne hábil para incutir a mística da liberdade. Não poderemos encaminhar o individuo na senda do civismo e da personalidade sem prepará-lo no seu primarismo, habilitando-o a compreender que é muito melhor viver gozando os atributos espirituais, convencionando regras morais, adquirindo 
princípios que sublimam a Política e a Ética, assegurando o bemestar, enaltecendo a virtude, divinizando a continuidade da espécie, garantindo a evolução criadora e convencionando a justiça de cada qual ter e fazer o que lhe compete - sintese da educação.

\section{CONCI USÕES}

Atendidos os interêsses individuais relativos a fatôres primários de valorização, estará o homem preparado para aceitar as convenções sociais decorrentes da fase civica e encarnadas no cidadão.

Na sua integração de valôres da pessoa humana é o cidadão levado a conceituar o Estado como Instituição formada para servi-lo. O regime totalitário arvora-se no protetor de indivíduo.

Um Estado representa sempre um Poder coercitivo. Procurando contudo educar intensamente e com amplitude, mantendo-se fiel aos preceitos de justiça social, verá automàticamente dimınuído seu papel coator dado que os cidadãos não se utilizam totalmente de suas prerrogativas de liberdade. O resultado final será sempre o siștema convencional de vida política - o regime democrático.

Com o progresso da técnica de comunicações existe no mundo de hoie um surto de intromissão cultural violento levando aos povos a consciência preponderante de seus direitos. Os valôres imanentes da natureza constituem mais que nunca o objeto de reivindicações visando à posse de fatôres primários e instintivos de valorização do gênero humano.

As condições e a conjuntura brasileiras de evolução e de desenvolvimento, em seu estágio de potencial natural de riquezas acessiveis e inexploradas, obrigam a atenções especiais e decididas para resguardá-las, preservá-las e aproveitá-las demonstrando capacidade e determinação.

As ações de valorização humana - qualificando nas necessidades individuais. atendendo a prerrogativas civicas dignificando na personalidade, - plasmarão os ideais de liberdade sem licenciosidade, - unificarão o pensamento na Segurança Nacional. aumentarão os valôres de Poder e imporão os direitos de Soberania.

Em qualquer tempo será ultrapassada a fase de Segurança Nacional quando na luta pela valorização humana chegarmos ao acesso da Cultura ao maior volume da população do Planêta. Em tal etapa, já a Ética, que é o Respeito à Vida, estará 
incorporada ao acervo global de Valorização Humana dos Chefes e Lideres. Poderá haver a transmutação em Segurança da Terra se a tanto nos conduzir a Ciência no seu esfôrço a procura da Verdade Universal.

\section{ANEXO N: 1}

POPULAÇAO MUNDIAL, RENDA E PRODUÇAO ALIMENTAR

Conferência: Conceito de valorização humana

O crescimento da população da Terra tem se acelerado sensivelmente de 1650 a 1750 , avançando de uma taxa anual de $0,3 \%$ a $0,5 \%$ no Século seguinte, atingindo 0,8 de 1850 a 1950 . Dêste ano até 1956 a taxa se elevou a $1,7 \%$ correspondendo em nossos dias a um aumento absoluto anual de 45 milhões, e, por dia 125.000. Em 41 anos duplicará, calculando-se em 5,7 bilhões de habitantes para o ano 2.000. Em 1957 a população elevava-se a 2.795 milhóes com uma taxa de crescimento aproximadamente de $2 \%$.

Os recursos alimentares no mundo têm aumentado na média de $3 \%$, sendo que a Ásia tevé uma aumento de $10 \%$ a mais em 1958 em relação ao ano anterior. A média para o resto do mundo é de $2 \%$.

São baixos os valôres de produção "per capita" da América do Sul, incluído o Brasil. O conjunto somou US\$ 300.00 enquanto os países anglo-saxões ela se elevou a US\$ 2.100.00.

Uma fração elevada ainda da Renda Nacional dos paises latino americanos provém das atividades agropecuárias (primárias), ou seja $30 \%$, comparada com $5 \%$ dos paises anglo-saxões. Nas atividades secundárias as cifras comparativas são as seguintes: $25 \%$ e $40 \%$ respectivamente.

A produção de aço, base das atividades econômicas secundárias as cifras comparativas são as seguintes: $25 \%$ e $40 \%$ respectivamente.

A produção de aço, base das atividades econômicas secundárias (industriais), somou apenas 3 milhões de toneladas sôbre 107 milhões dos paises anglo-saxões (1957).

No comércio internacional a exportação elevou-se a 8,6 bilhões de US\$ e a importação a 9,3 bilhões. O grupo anglosaxão com população quase igual aos países latino-americanos, as exportações foram três vêzes maiores, ou 25,8 bilhões de US\$ somando as importações 20,9 bilhões. Na América Latina o saldo negativo foi de 0,7 bilhões e nos paises em comparação houve um saldo positivo de 4,9 bilhões de US $\$$. 
A alimentação na América Latina é insuficiente, embora seja gasto uma média de $50 \%$ do orçamento familiar em alimentos, bebida e fumo comparados aos $30 \%$ de gasto nos países anglosaxões.

O economista norte-americano Peter F. Drucker fêz as seguintes declarações:

"Menos de um décimo da população mundial vive no Continente Norte-Americano e desfruta de dois têrços a três quartos da Renda e dos produtos mundiais. Cêrca de $75 \%$ da humanidade que vive de uma renda anual de menos de cem dólares "per capita" não tem. O conjunto, mais do que dez por cento da produção mundial. Esta disparidade econômica é maior do que qualquer outra que já se tenha verificado no acidente desde o advento da revolução industrial. E' uma disparidade crescente; a distância entre os países econômicamente desenvolvidos e os subdesenvolvidos tem aumentado em vez de diminuir, não só nos últimos cinqüenta anos como também nos últimos dez anos".

(Robert C. Cook - "Revista Brasileira de Estatística", Julho-Dez. - 1959, pág. 196).

\section{BIBLIOGRAFIA}

(1) Statistical Year Book of United Nations - 1958.

(2) Giorgio Mortara - Os Estudos Demográficos e a Politica da população da América Latina "Revista Bras. de Estatística" Julho-Dez. - 1959, pág. 117.

- Alfred SAuvy - Da Provisão demográfica à previsão econômica. Idem., Janeiro-Junho de 1959, pág. 129.

- Baugnee Lin - Estatisticas Mundiais de Educação. - Idem, JaneiroJunho - 1959, pág. 31 .

- RoBert Cook - Idem, Comentários, Julho-Dezembro, 1959, pág. 196. 